\author{
Wu Wei · Charlene C. K. Keh · Chao-Jun Li \\ Rajender S. Varma
}

\title{
Water as a reaction medium for clean chemical processes
}

Published online: 30 November 2004

(C) Springer-Verlag 2004

(Anastas and Warner 1998). The studies of green chemistry have led to the development of cleaner and relatively benign chemical processes with many new technologies being developed each year. Among them, there is a large proportion of effort that has been devoted to the use of non-traditional solvent for chemical synthesis. These unconventional media include solventless (Cherouvier et al. 2001; Tanaka 2003; Togo and Hirai 2003; Varma 1999; Varma 2000a; Varma 2000b; Varma 2001), water (Chan and Issac 1996; Li 1993; Li 1996; Li 2002; Li and Chan 1997; Li and Chan 1999), supercritical $\mathrm{CO}_{2}$ (Devetta et al. 1999; Ishii and Oi 1998; Jessop and Leitner 1999; Matruda et al. 2001; Wei et al. 2002), ionic liquids (Rogers and Seddon 2002; Wasserscheid and Keim 2000), perfluorinated solvent (Gladysz and Curran 2002; David et al. 2002; Moineau et al. 1999), and some others (Harano et al. 2000; Westacott et al. 2001). During these explorations, a familiar question is frequently asked even within the green chemistry community about the relative greenness of a medium over others. There is no clear answer to this question if the context of the discussion is not defined. For example, water is commonly considered as a benign solvent for its non-toxicity and abundant natural occurrence, yet in the semiconductor industry, wastewater contaminated with trace amount of metals is a serious environmental problem (Aoki et al. 2002; Uchida et al. 2002). Thus, it is important to recognize that there is no universal best solvent for all chemical processes. Instead, the different choices provide various alternatives for the end-users to select based on their own assessments of overall environmental impact. Water is undoubtedly the cleanest solvent on earth. The use and release of "clean water" will have the least impact to the environment. However, it should be stressed that the release of a large amount of uncleaned (untreated) water has been a major problem. In this article we will briefly discuss, with selected examples, some of the main advantages of using water as a reaction medium to develop cleaner chemical processes. 


\section{(1) Direct utilization of water-soluble compounds and renewable materials}

The first common advantage of using water as solvent for clean technology is the opportunity to directly utilize water-soluble compounds and renewable materials such as carbohydrates without the necessary derivatizations. However, in order to accomplish this goal, chemical reactions that can tolerate water and reactive functional groups such as hydroxyl, amine, and acids should be developed. Within the past two decades many reactions that are conventionally believed to proceed only in organic solvents have been developed in water. Since the seminal work of Breslow on aqueous Diels-Alder reactions (Breslow 1999), there have been profound research activities of developing organic reactions in aqueous media. Among the many significant developments in the field are the Diels-Alder (including hetero-Diels-Alder) and sigmatropic rearrangements (Chandrasekhar et al. 2002; Grieco 1991; Libineau et al. 1992; Loh et al. 1996; Otto and Engberts 1999; Otto et al. 1998; Otto et al. 1996; Wipf and Ribs 2001), the catalytic hydrogenations and hydroformylations, the metal-mediated carboncarbon bond formations, the water-tolerant Lewis acid catalysis (Heeres et al. 2001; Haumann et al. 2002; Kobayashi and Manabe 2002; Gu et al. 2001; Li 2002; Li et al. 2002a; Li et al. 2002b; Lindstoem 2002; MunozMoniz et al. 2003; Paganelli et al. 2000; Shimizu et al. 2000; Shirakawa 2001; Tin et al. 1999) including solid acids (Okuhara 2002), transition-metal catalyzed carbon-carbon bond formations ( $\mathrm{Li}$ et al. 1998; $\mathrm{Li}$ et al. 2002a; Li et al. 2002b; Zhang et al. 2000), radical reactions (Poonkodi and Anbalagan 2001), and various asymmetric carbon-carbon bond formations in water (Manabe and Kobayashi 2002). High temperature water has also shown to be a promising medium for new chemistry (Shaw et al. 1991). These reactions provided the possibility of directly modifying water-soluble and renewable materials in water without the necessary protection-deprotection sequences that are commonly associated with conventional chemistry, thus reducing the overall synthetic steps. An example is the higher carbon-sugar synthesis from carbohydrate by Chan (Chan and $\mathrm{Li}$ 1992) and Whitesides (Gao et al. 1994) (Scheme 1).

\section{(2) Catalyst recycling and product isolation via phase separation}

Another potential opportunity of clean chemical synthesis in water is the development of catalytic processes that can simplify catalyst recycling and product isolation. While designing ideal catalytic processes for clean synthesis in water, a key is to develop catalysts that are soluble in water. Ideally, the reactant and the product should have no or very little water solubility. As a result, the product can be isolated by simple phase separations

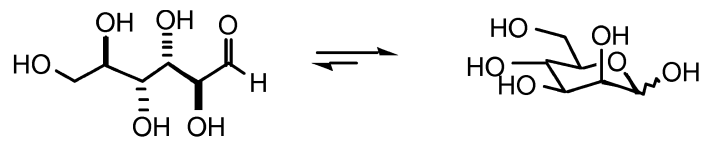

$\ln / \mathrm{H}_{2} \mathrm{O} \Gamma_{\mathrm{Br}} \mathrm{CO}_{2} \mathrm{Me}$

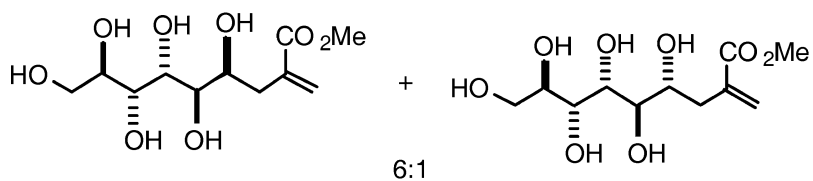

$\mathrm{O}_{3}$<smiles>COC(=O)CC(O)C(O)[C@H](O)[C@H](O)[C@H](O)CO</smiles>

1

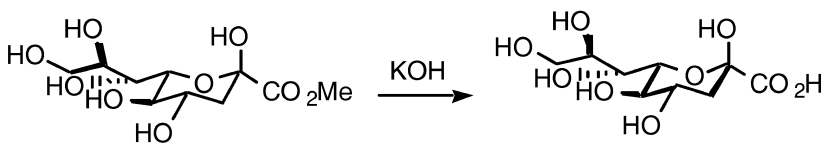

(+) KDN

Scheme 1 Synthesis of sialic acid in water

and the catalyst can be recycled readily. Through this strategy, it is possible to recycle the aqueous catalyst solution for an extended period of time without the need either to discharge it or to regenerate it.

A second key to develop clean catalysis in water is to develop reactions with high atom efficiency. This is important as low atom efficiency will lead to the accumulation of unwanted materials in the solution, which will eventually require the change and discharge of the catalyst solution. Examples of successfully developed catalytic reactions include catalytic hydrogenations, hydroformylations, Wacker's oxidation, and some polymerization reactions.

Hydrogenation, together with hydrocyanation, hydrosilylation, and hydrostannation, are useful transition metal-catalyzed reactions in organic synthesis (Augustine 1965; Freifelder 1971; Freifelder 1978; Rylander 1979; Rylander 1985). The first successful catalytic hydrogenation in aqueous solution was reported in 1975 by using a catalyst having water-soluble phosphine ligands (Joo and Beck 1975). Since then, both hydrogenation of $\mathrm{C}-\mathrm{C}$ unsaturated bonds and $\mathrm{C}-\mathrm{O}$ double bonds in aqueous medium have been extensively studied. For example, Joo and Benyei have shown that by using 
$\mathrm{RuCl}_{2}$ (TPPMS) $)_{2}$ and sodium formate as hydrogen donor, a variety of aromatic and $\alpha, \beta$-unsaturated aldehydes were transformed to the corresponding saturated alcohols in aqueous solution (Benyei and Joo 1990; Joo and Benyei 1989). Many excellent asymmetric hydrogenation processes have also been developed (Toth et al. 1990). A highly regio- and stereoselective hydrosilylation of terminal alkyne has been developed $(\mathrm{Wu}$ and $\mathrm{Li}$ 2003).

The hydroformylation process is one of the most successful applications of aqueous medium catalysis in industrial manufacture. A series of patents in 1982 described the reaction process (Cornils et al. 1982), the recovery of rhodium catalyst (Gaertner et al. 1984a), and the preparation of water-soluble sulfonated phosphane ligands (Gaertner et al. 1984b). The best known hydroformylation is Ruhrchemie/Rhône-Poulenc's process (Bexten et al. 1986) that uses $\mathrm{HRh}(\mathrm{CO})(\mathrm{tppts})_{3}$ as catalyst (Scheme 2). The product is separated from the catalyst solution by a simple phase separation, and the catalyst solution is recharged to the reactor for further reaction. During the process, the loss of rhodium catalyst in the organic phase is negligible.

$$
\mathrm{RCH}=\mathrm{CH}_{2}+\mathrm{CO}+\mathrm{H}_{2} \stackrel{\text { cat.[HRh }(\mathrm{CO})\left[\mathrm{P}\left(\mathrm{PhSO}_{3} \mathrm{Na}\right)_{3}\right]}{\mathrm{H}_{2} \mathrm{O}} \mathrm{RCH}_{2} \mathrm{CH}_{2} \mathrm{CHO}
$$

Scheme 2 Ruhrchemie/Rhône-Poulenc's hydroformylation process

The Wacker oxidation involves the oxidation of olefin with oxygen or air in water (Smidt et al. 1962). In one example, ethylene is more than $99 \%$ converted to acetaldehyde when passed (together with the catalyst solution) once through a flow reactor at moderate pressure and medium temperatures. The acetaldehyde formed distills off while releasing the aqueous solution containing the catalyst, which can be pumped back to the reactor and reused again. Another interesting development is the aqueous polymerization processes among which the single-site olefin polymerization reaction using water-soluble transition metal catalysts are particularly prominent (Younkin et al. 2000).

Carbon-carbon bond formation via $\mathrm{C}-\mathrm{H}$ activation in water is another potential clean process that can have both high atom efficiency and easy recycling of the catalyst solution. One example of such $\mathrm{C}-\mathrm{H}$ activationbased carbon-carbon bond formation process is the addition of alkynes to imines (Scheme 3). Enantioselective alkyne-imine addition is also possible in water (Li and Wei 2002b; Wei and Li 2002).

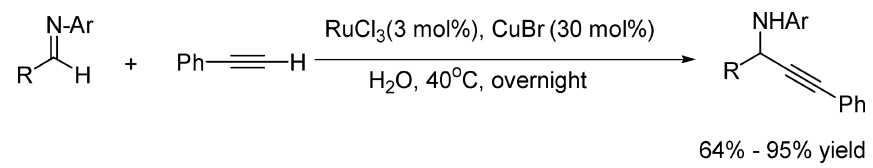

Scheme 3 Enantioselective alkyne-imine addition in water

\section{(3) The combination of electrochemistry-solar chemistry in water}

Additional examples of developing clean chemical synthesis in water is the development of electrochemical oxidations and reductions as well as solar-cell-based chemical technologies. As an example, the production of adiponitrile is an important industrial process involving the electro-hydrodimerization (EHD) of acrylonitrile. Adiponitrile is used as an important precursor for hexamethylenediamine and adipic acid, the monomers required for the manufacture of nylon-66 polymer (Danly and King 1991). A high-yield adiponitrile synthesis (Baizer 1980) was realized via an electrochemical process by using a concentrated solution of certain quaternary ammonium salts (QAS) together with lead or mercury cathodes (Scheme 4).

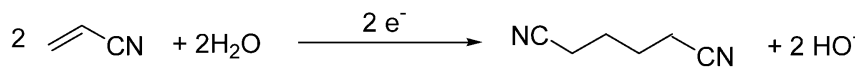

Scheme 4 Electrochemical process for adiponitrile synthesis

The prospect of utilizing solar energy for chemical processes is yet another clean technology. In the sunshine, decomposition of 2,6-dinitrotoluene and $m$ nitrotoluene in water has been realized $(\mathrm{Yu}$ and $\mathrm{Hu}$ 2001). Similarly, degradation of 3,4-dichloropropionamine has also been reported in the presence of $\mathrm{TiO}_{2}$ in aqueous media (Pathirana Hema and Maithreepala 1997). These reactions provide the basis for design of synthetic processes. In an aqueous solution, and in the presence of a photoinitiator, the isomerization of bicyclo [2,2,1]hepta-2,5-diene-2,3-dicarboxylic acid can occur which is promising for the preparation of nobornadiene derivatives and for solar energy storage (Wang et al. 1996).

\section{(4) The biocatalytic processes}

As most biological processes and enzymatic reactions occur in aqueous media, there are ample opportunities of combining enzymatic reactions with chemical reactions in water.

Because water is a favored solvent in biocatalysis processes, many biocatalytic protocols use water-organic solvent biphasic systems as the reaction medium, wherein the organic phase could help remove the products being generated from the aqueous phase. For example, phospholipid-catalyzed transesterification or hydrolysis of phospholipids, which is useful for the preparation of a variety of differently substituted phospholipids, diacylglycerols and ceramides, can be conducted in an $\mathrm{H}_{2} \mathrm{O}$ /butyl acetate biphasic medium (Barenholz and Amselem 2000). A practical and efficient asymmetric reduction of ketones via enzymatic catalysis was developed in a water $/ n$-heptane system (Harald et al. 2003; Jonsson et al. 1999). Enzymatic oxidative 
polymerization of cresol in an aqueous medium provides an alternative route for the synthesis of phenolic polymers (Sangrama et al. 2002), which are structurally different from the traditional phenol-formaldehyde-based polymers. Biocatalytic epoxidation of vinyl aromatic compounds has also been performed in aqueous medium for the preparation of selected optically active epoxides with high enantiomeric purity (Schmid et al. 2001).

\section{(5) The use of ultrasound and microwave for energy efficiency}

Finally, for many chemical processes, a major adverse effect to the environment is the consumption of energy for heating and cooling. To overcome such problems, it is highly desirable to develop efficient methods that use alternative energy sources such as ultrasound and microwave irradiation to facilitate chemical reaction. Ultrasonic irradiation enhances the chemical reaction and mass transfer via the process of acoustic cavitation (Luche 1998).

Ultrasound: in aqueous reaction media, the sonolysis of the $\mathrm{O}-\mathrm{H}$ bond is a predominant phenomenon that occurs in the gas phase of the bubble generating hydrogen and hydroxyl radicals:

$$
\mathrm{H}_{2} \mathrm{O} \stackrel{())))}{\longrightarrow} \mathrm{H}^{\cdot}+\mathrm{HO}^{\circ}
$$

The sonochemically formed oxidizing species such as hydroperoxyl radicals have been detected that originate from reaction of dioxygen with hydrogen (Henglein 1993). In a cavitating liquid, the reaction can take place in three regions namely gaseous phase inside the bubble, the limit shell surrounding it and in the bulk solution. The sonolysis of amphiphilic compounds in water takes place leading to hydroxylation followed by subsequent oxidations by ensuing hydroxyl radicals. Thus, it has potential application in the degradation of pollutants in water even at low concentration and avoiding the energy-intensive concentration efforts (Petrier et al. 1992b). More useful environmental applications of sonication have been advanced in conjunction with photocatalytic or electrochemical method (Benahcene et al. 1995). Interfacial reactivity is apparent in the oxidation of hindered secondary amines (Petrier et al. 1992a). In presence of oxygen bubbling, stable nitroxides are produced as a result of hydroxyl radical abstraction of the hydrogen followed by the reaction of oxygen with nitrogen-centered radicals (Scheme 5). In the absence of

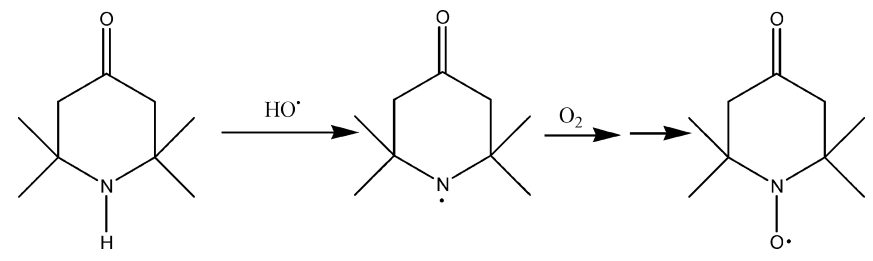

Scheme 5 Formation of stable nitroxides oxygen, when argon is bubbled, nitroxides are not formed. Sonication may greatly improve the rates and yields of organometallic reactions via enhancement of the electron transfer processes.

In view of the known efficiency of surfactant-pillared clays to act as a dispersed solid phase in a triphasic catalyst system (Lin and Pinnavia 1991), relatively benign modified clays have been prepared by introducing 3-aminopropyl-triethoxysilane and surfactants into the clay interlayer. Such organo-clay assemblies have proven useful in some useful organic transformations such as preparation of benzyl cyanides, thiocyanides and alcohols from the corresponding benzyl halides and sodium cyanide, thiocyanide and hydroxide respectively (Varma et al. 1999a). In this context it is important to mention 18-crown-6 "doped" clay as a recyclable phase transfer catalyst in nucleophilic substitution reactions that provides relatively improved yields of alkyl azides from alkyl bromides and sodium azide in aqueous media (Varma et al. 1999b).

Further, it has been shown that alkyl halides and $\alpha$ tosyloxyketones afford the corresponding azide derivatives upon treatment with aqueous sodium azide $\left(\mathrm{NaN}_{3}\right)$ under triphase catalysis or ultrasound irradiation conditions (Varma and Kumar 1998; Varma and Naicker 1998). The use of surfactant pillared clay materials and sonochemistry has been compared in such nucleophilic substitution reactions that have afforded a practical synthesis of azides and $\alpha$-azidoketones involving triphase catalysis. Among the nucleophilic substitution reactions, a study has been conducted to explore the viability of ultrasound as a substitute for a phasetransfer catalyst (PTC), by comparing the results under various set of conditions that include triphase catalyst under classical (reflux) conditions; triphase catalyst in conjunction with ultrasound irradiation at very low temperature; and finally, a two-phase catalyst-free system using only ultrasound irradiation (Varma et al. 1999c).

In a typical example, the alkyl bromide or $\alpha$-tosyloxyketones and aqueous $\mathrm{NaN}_{3}$ are admixed in the molar ratio 1:1.2 and refluxed with continuous stirring in the presence of organo-clay material under classical conditions or under ultrasound irradiation with or without organo-clay assembly (Scheme 6).

Under the influence of ultrasound irradiation, it has been observed that a favorable acceleration in reaction rate occurs when compared to classical conditions (i.e. under reflux). The addition of catalytic amounts of surfactant-pillared clays further facilitated the reaction, thereby indicating a synergistic effect of ultrasound on triphase catalyst system. However, the successful reaction with sonication in the absence of pillared clay indicates that ultrasound can indeed substitute for a phase-transfer catalyst, thereby providing an attractive alternative for the nucleophilic substitution reactions (Varma 1999c).

Microwave $(M W)$ irradiation, an unconventional energy source, has been used for a variety of applica- 


$$
\begin{aligned}
& \begin{array}{c}
\text { With or without surfactant } \\
\text { pillared clay }
\end{array} \\
& \mathrm{RX}+\mathrm{NaN}_{3} \stackrel{\text { pillared clay }}{\text { ))) ), at } 0-5^{\circ} \mathrm{C}, 2-6 \mathrm{~h}} \mathrm{RN}_{3}+\mathrm{NaX} \\
& \mathrm{X}=\mathrm{Br} ; \mathrm{R}=\mathrm{C}_{6} \mathrm{H}_{5} \mathrm{CH}_{2}, 4-\mathrm{NO}_{2} \mathrm{C}_{6} \mathrm{H}_{4} \mathrm{CH}_{2}, 2-\mathrm{MeC}_{6} \mathrm{H}_{4} \mathrm{CH}_{2}, 3-\mathrm{MeC}_{6} \mathrm{H}_{4} \mathrm{CH}_{2} \text {, } \\
& 4-\mathrm{MeC}_{6} \mathrm{H}_{4} \mathrm{CH}_{2}, \mathrm{C}_{10} \mathrm{H}_{17} \\
& \begin{array}{l}
\mathrm{OTs} \\
\begin{array}{l}
\mathrm{R}=\mathrm{C}_{6} \mathrm{H}_{5}, 4-\mathrm{MeC}_{6} \mathrm{H}_{4}, 4-\mathrm{ClC}_{6} \mathrm{H}_{4}, 4-\mathrm{OMeC}_{6} \mathrm{H}_{4}, \mathrm{CH}_{3} \mathrm{CH}_{2} \\
\mathrm{R}^{\prime}=\mathrm{H}, \mathrm{CH}_{3}
\end{array}
\end{array}
\end{aligned}
$$

Scheme 6 Synthesis of azides and $\alpha$-azidoketones via nucleophilic substitution reactions

tions including organic synthesis (Hayes 2002; Pillai et al. 2002; Varma 2002a; Varma 2002b; Varma 2002c) wherein chemical reactions are accelerated because of selective absorption of microwave energy by polar compounds or intermediates, non-polar molecules being inert to the MW dielectric loss. Although this non-ionizing radiation is incapable of breaking bonds, coupling it with the traditional heterogeneous reactions could result in their rate acceleration at ambient pressure.

Among the numerous facile organic transformations (Bose et al. 1991), the hydrolysis of organic compounds under the influence of aqueous acids or bases usually requires extensive heating. In such synthetic reactions MW heating can hydrolyze amides, nitriles, esters and peptides much more efficiently. As an example, the hydrolysis of peptides can be accomplished in 15-20 min using MW irradiation as compared to 12 or more hours of conventional conductive heating (Majetich and Hicks 1995). High-temperature aqueous reactions in continuous (CMR) and batch (MBR) microwave reactors have been explored and the technique has been used to conduct a variety of organic reactions in water. The advantages include less waste generation, safe handling and low cost as demonstrated in the following examples.

In general, the hydrolysis of tertiary amides is difficult to achieve even at reflux conditions. A morpholinide derivative has been successfully hydrolyzed to afford 4-tbutylcyclopent-1-enoic acid $(70 \%)$ in $10 \mathrm{~min}$ under microwave irradiation whereas only $40 \%$ product is obtainable after a 4-h reflux under classical condition (Raner et al. 1995) (Scheme 7).

Under optimized reaction conditions specific product formation is achievable as has been demonstrated in the ortho-Claisen rearrangement of allyl phenyl ether or reaction of carvone in water (An et al. 1997). Heating of carvone in water at $210{ }^{\circ} \mathrm{C}$ afforded 8-hydroxy- $p$-menth6-en-2-one in $10 \mathrm{~min}$ whereas at $250{ }^{\circ} \mathrm{C}$ carvone isomerized to carvacrol in almost quantitative yield. In a batch reactor, allyl phenyl ether upon heating in water delivered different products at various temperatures. The Claisen rearrangement product, 2-allylphenol, $(56 \%)$ is obtained at $200{ }^{\circ} \mathrm{C}, 2$-(2-hydroxyprop-1yl)phenol $(37 \%)$ at $230{ }^{\circ} \mathrm{C}$ and 2-methyl-2,3-dihydrofuran $(72 \%)$ at $250{ }^{\circ} \mathrm{C}$ (Bagnell et al. 1996).

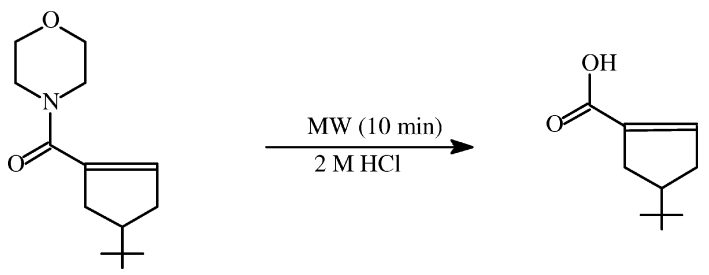

Scheme 7 MW-assisted hydrolysis of tertiary amides

The Fischer indole synthesis of 2,3-dimethylindole $(67 \%)$ has been accomplished in water from phenylhydrazine and butan-2-one at $220{ }^{\circ} \mathrm{C}$ within $30 \mathrm{~min}$ (Strauss and Trainer 1998) thus circumventing the use of preformed hydrazone or any acid (Scheme 8).<smiles>NNc1ccccc1</smiles><smiles>CCC(C)=O</smiles><smiles>Cc1[nH]c2ccccc2c1C(C)O[Na]</smiles>

Scheme 8 Fischer indole synthesis in aqueous medium

The conventional methods for decarboxylation of indole-2-carboxylic acid to indole are not environmentally benign as they often require pyrolysis or thermolysis in quinoline or pyridine derivatives and in the presence of various copper salts. The decarboxylation of indole-2-carboxylic acid occurs almost quantitatively in water at $255^{\circ} \mathrm{C}$ within $20 \mathrm{~min}$.

3-Methylcyclopent-2-enone is usually prepared by an intramolecular Claisen-Schmidt condensation from 2,5hexandione under strongly basic conditions. The major drawback is that the product also undergoes aldol and Claisen-Schmidt condensation thus lowering the yield. Under microwave irradiation condition at $200{ }^{\circ} \mathrm{C}$, however, competing reactions are suppressed and the desired enone is obtained in $94 \%$ yield since the base is employed in much less concentration (Bagnell et al. 1997).

The formation of inorganic salts accounts for the major waste generation in the production of various pharmaceuticals and fine chemicals in view of the frequent neutralization of basic or acidic solutions. The MW protocols using high-temperature water as the reaction medium are especially attractive in this context because of the selectivity and less usage of the acidic or basic agent that eventually reduces the requirement for neutralization (Strauss 1999).

Near critical water $(\mathrm{NCW})$, generated in stainless steel pressure vessels or microwave-irradiated Teflon or glass reactors, is proving to be a useful green reaction medium for a variety of organic transformations as the properties of $\mathrm{NCW}$ can be fine tuned to attain selectivity for a desired molecule among several possible reaction products. With the increase in temperature and pressure, 
the dielectric constant and hydrogen bonding decreases and the water ionization and solubility of the organic molecules increases. These extreme changes in properties of NCW have been exploited in the synthesis of naturally occurring isochoumarins of medicinal interest that are normally obtained by the aromatic substitution using activated methylene compounds in organic solvent in the presence of a base and stoichiometric amounts of copper catalyst. Pressurized hot water has proven to be effective reaction medium for such reactions (Bryson et al. 2003b) with added benefit of selectivity of forming 1 or 2 (Scheme 9).

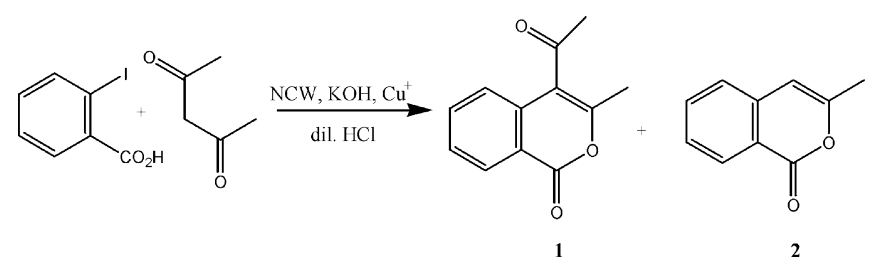

Scheme 9 Preparation of isocoumarins in near critical water $(\mathrm{NCW})$ medium

The approach has been further extended to the syntheses of nitrogen heterocycles where selective reduction, cyclodehydrations (Pfitzinger and Friedlander syntheses), Suzuki coupling and ligand exchange reactions have been effected in water with potential recycling of the catalyst in aqueous medium (Bryson et al. 2003a).

In a similar approach, the synthesis of medicinally significant, 2-phenylbenzimidazole from 1,2-phenylenediamine and benzoic acid has been achieved in high temperature water (Scheme 10).

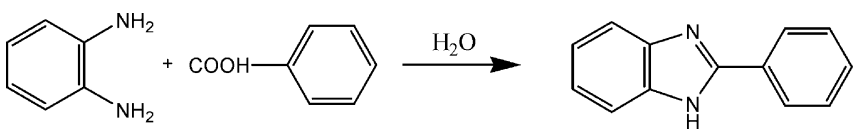

Scheme 10 Synthesis of 2-phenylbenzimidazole in water

The proper control of the reactions conditions provide high yield of the product and the solvation properties of water has been exploited by allowing the reaction product to crystallize out from the aqueous medium upon cooling (Dud et al. 2003).

\section{Conclusion}

Green chemistry is a rapidly developing new field that provides us a proactive avenue for the sustainable development of future science and technologies. When designed properly, clean chemical technology can be developed in water as a reaction medium. The technologies generated from such green chemistry endeavors may often be cheaper and more profitable.

Acknowledgements We want to thank all colleagues who have helped the development of green chemistry and the chemistry in water. We also thank support of our research provided by the US
NSF, EPA, and the US-EPA green chemistry joint program for a sustainable environment.

\section{References}

An J, Bagnell L, Cablewski T, Strauss CR, Trainer RW (1997) Applications of high-temperature aqueous media for synthetic organic reactions. J Org Chem 62:2505

Anastas PT, Warner (1998) Green chemistry: theory and practice. Oxford University Press, Oxford

Aoki S, Onozawa I, Horiuchi T Jpn. Kokai Tokkyo Koho (2002) Method for utilization of waste heat of wastewater from production of pure water for manufacture process of semiconductor wafers. JP 2002016036.

Augustine RL (1965) Catalytic hydrogenation. Marcel Dekker, New York

Bagnell L, Cablewski T, Strauss CR, Trainer RW (1996) Reactions of allyl phenyl ether in high-temperature water with conventional and microwave heating. J Org Chem 61:7355

Bagnell L, Bliese M, Cablewski T, Strauss CR, Tsanaktsidis J (1997) Environmentally benign procedures for the preparation and isolation of 3-methylcyclopent-2-en-1-one. Aust J Chem 50:921

Baizer MM (1980) The electrochemical route to adiponitrile. 1. Discovery. Chemtech 10:161

Barenholz Y, Amselem S (2000) Enzymatic preparation of phospholipids in aqueous media employing a water/solid silica gel particle interface. PCT Int Appl WO 0077183

Benahcene A, Labbe P, Petrier C, Reverdy G (1995) Effects of ultrasonically induced cavitation on electrochemical processes. Cell geometry and frequency effects. New J Chem 19:989

Benyei A, Joo F (1990) Organometallic catalysis in aqueous solutions: the biphasic transfer hydrogenation of aldehydes catalyzed by water-soluble phosphine complexes of ruthenium, rhodium and iridium. J Mol Catal 58:151

Bexten L, Cornils B, Kupies D (1986) Separation and purification of salts of diphenyl(m-sulfophenyl)phosphine, phenylbis $(m-$ sulfophenyl)phosphine, and/or tris( $m$-sulfophenyl)phosphine. (Ruhrchemie AG), DE-B 3431643

Bose AK, Manhas MS, Ghosh M, Shah M, Raju VS, Bari SS, Newaz SN, Banik BK, Chaudhary AG, Barakat KJ (1991) Microwave-induced organic reaction enhancement chemistry. 2. Simplified techniques. J Org Chem 56:6968

Breslow R (1991) Hydrophobic effects on simple organic reactions in water. Acc Chem Res 24:159

Bryson TA, Gibson JM, Stewart JJ, Voegtle H, Tiwari A, Dawson JH, Marley W, Harmon B (2003a) Synthesis of quinolines, pyridine ligands and biological probes in green media. Green Chem 5:177

Bryson TA, Stewart JJ, Gibson JM, Thomas PS, Berch JK (2003b) Green heterocycle synthesis, isochromenones and artemidin. Green Chem 5:174

Chan TH, Isaac MB (1996) Organometallic-type reactions in aqueous media mediated by indium: application to the synthesis of carbohydrates. Pure Appl Chem 68:919

Chan TH, Li CJ (1992) A concise chemical synthesis of (+)-3deoxy-D-glycero-D-galacto-nonulosonic acid (KDN). J Chem Soc Chem Commun 747

Chandrasekhar J, Shariffskul S, Jorgensen WL (2002) QM/MM simulations for Diels-Alder reactions in water: contribution of enhanced hydrogen bonding at the transition state to the solvent effect. J Phys Chem B 106:8078

Cherouvier JR, Boissel J, Carreaux F, Bazurean J (2001) A stereoselective route to 3-methyl-2-methylsulfanyl-5-ylidene-3,5dihydroimidazol-4-one derivatives and precursor of Leucettamine B. Green Chem 3:165

Cornils B, Hibbel J, Konkol W, Lieder B, Much J, Schimd V, Wiebus E (1982) Aldehydes. (Ruhrchemie AG), DE-B 3234701

Danly DE, King CJH (1991) In: Lund H, Baizer MM (eds) Organic electrochemistry, 3rd edn. Marcel Dekker, New York 
David J, Schwarz GP, Pogorzelec P (2002) Hydroformylation in perfluorinated solvents; improved selectivity, catalyst retention and product separation. Tetrahedron 58:3901

Devetta L, Giovanzana A, Canu P, Bertucco A, Minder BJ (1999) Kinetic experiments and modeling of a three-phase catalytic hydrogenation reaction in supercritical $\mathrm{CO}_{2}$. Catal Today 48:337

Dud, LM, Venardou, E, Garcia-Verdugo, E, Licence, P, Blake, AJ, Wilson, C, Poliakoff, M (2003) Synthesis of benzimidazoles in high-temperature water. Green Chem 5:187

Freifelder M (1971) Practical hydrogenation. Wiley, New York

Freifelder M (1978) Catalytic hydrogenation in organic synthesis, Wiley-Interscience, New York

Gaertner R, Cornils B, Bexten L, Kupies D (1984a) Recovery of water-soluble, rhodium containing hydroformylation catalysts. (Ruhrchemie AG), DE-B 3235029

Gaertner R, Cornils B, Springer H, Lappe P (1984b) Sulfonated arylphosphines. (Ruhrchemie AG), DE-B 3235030

Gao J, Harter R, Gordon DM, Whitesides GM (1994) Synthesis of KDO using indium-mediated allylation of 2,3:4,5-di- $O$-isopropylidene-D-arabinose in aqueous media. J Org Chem 59:3714

Gladysz JA, Curran DP (2002) Fluorous chemistry: from biphasic catalysis to a parallel chemical universe and beyond. Tetrahedon 58:3823

Grieco PA (1991) Organic chemistry in unconventional solvents. Aldrichim Acta 24:59

Grieco PA (1998) Organic synthesis in water. Thomson Science, Glasgow

Gu W, Zhou W, Gin D (2001) A nanostructured, scandium-containing polymer for heterogeneous Lewis acid catalysis in water. Chem Mater 13:1949

Harald G, Werner H, Stefan B, Karlheinz D, Tien VN, Claudia R, Hendrik H, Kofi A (2003) Practical asymmetric enzymatic reduction through discovery of a dehydrogenase-compatible biphasic reaction media. Org Lett 5:173

Harano Y, Sato H, Hirata F (2000) Solvent effects on a DielsAlder reaction in supercritical water: RISM-SCF study. J Am Chem Soc 122:2289

Haumann M, Yildiz H, Koch H, Schomacker R (2002) Hydroformylation of 7-tetradecene using Rh-TPPTS in a microemulsion. Appl Cata A Gen 236:173

Hayes BL (2002) Microwave synthesis: chemistry at the speed of light. CEM Publishing, Metthew

Heeres A, Van Doren HA, Gotlieb KF, Bleeker IP, Bergsma J, Kellogg RM (2001) Synthesis, analysis and reduction of 2-nitropropyl starch. Carbohydrate Res 330:191

Henglein A (1993) In Mason, TJ (ed) Advances in sonochemistry, vol. 3. Jai Press, London, p 17

Ishii R, Oi K (1998) Reaction in supercritical $\mathrm{CO}_{2}$; an intercalation of 4-phenylazoaniline between layers of montmorillonite pillared with tetramethylammonium ions. Chem Commun1705

Jessop PG, Leitner W (1999) (eds) Chemical synthesis using supercritical fluids. Wiley-VCH, Weinheim

Jonsson A, Wehtje E, Adlercreutz P, Mattiasson B (1999) Thermodynamic and kinetic aspects on water vs. organic solvent as reaction media in the enzyme-catalyzed reduction of ketones. Biochim Biophys 313

Joo F, Beck MTT (1975) Formation and catalytic properties of water-soluble phosphine complexes. React Kinet Catal Lett 2:257

Joo F, Benyei AJ (1989) Biphasic reduction of unsaturated aldehydes to unsaturated alcohols by ruthenium complex-catalyzed hydrogen transfer. Organomet Chem 363:C19

Kobayashi S, Manabe K (2002) Development of novel Lewis acid catalysts for selective organic reactions in aqueous media. Acc Chem Res 35:209

Li CJ (1993) Organic reactions in aqueous media - with a focus on carbon-carbon bond formation. Chem Rev 93:2023

Li CJ (1996) Aqueous Barbier-Grignard type reaction: scope, mechanism, and synthetic applications. Tetrahedron 52:5643
Li CJ (2002) Quasi-Nature Catalysis: Developing C-C bond formations catalyzed by late transition metals in air and water. Acc Chem Res 35:533

Li CJ, Chan TH (1997) Organic reactions in aqueous media. Wiley, New York

Li CJ, Chan TH (1999) Organic syntheses using indium-mediated and catalyzed reactions in aqueous media. Tetrahedron 55:11149

Li CJ, Wei CM (2002a) Highly efficient Grignard-type imine additions via $\mathrm{C}-\mathrm{H}$ activation in water and under solvent-free conditions. Chem Commun 268

Li CJ, Wei CM (2002b) Enantioselective direct-addition of terminal alkynes to imines catalyzed by copper(I)pybox complex in water and in toluene. J Am Chem Soc 124:5638

Li CJ, Meng Y, Yi X, Ma J, Chan TH (1998) Manganese-mediated carbon-carbon bond formation in aqueous media: chemoselective allylation and pinacol coupling of aryl aldehydes. J Org Chem 63:7498

Li CJ, Haberman JX, Keh CCK, Yi X, Meng Y, Hua X, Venkatraman S, Zhang W, Nguyen T, Wang D, Huang T, Zhang, J (2002a) Organic reactions in water and other alternative media: metal-mediated carbon-carbon bond formations. ACS Symp Ser 819 American Chemical Society, Washington, DC, p 178

Li H, Tian H, Chen Y, Wang D, Li CJ (2002b) Novel chiral gallium Lewis acid catalysts with semi-crown ligands for aqueous asymmetric Mukaiyama aldol reactions. Chem Commun 2994

Libineau A, Ague J, Bellanger N, Caillebourdin S (1992) Waterpromoted organic synthesis using glyco-organic substrates: the Claisen rearrangement. J Chem Soc Perkin Trans 11631

Lin CL, Pinnavia TJ (1991) Organo clay assemblies for triphase catalysis. Chem Mater 3:213

Lindstoem UM (2002) Stereoselective organic reactions in water. Chem Rev 102:2751

Loh T, Pei J, Lin M (1996) Indium trichloride $\left(\mathrm{InCl}_{3}\right)$ catalysed Diels-Alder reaction in water. Chem Commun 2315

Luche JL (1998) Synthetic organic sonochemistry. Plenum Press, New York

Majetich G, Hicks RJ (1995) The use of microwave heating to promote organic reactions. J. Microwave Power Electromagn Energy 30:27

Manabe K, Kobayashi S (2002) Catalytic asymmetric carboncarbon bond-forming reactions in aqueous media. Chem Eur J 8:4094

Matruda T, Ohashi Y, Harada T, Yanagihara R, Nagasawa T, Nakamura K (2001) Conversion of pyrrole to pyrrole-2-carboxylate by cells of Bacillus megaterium in supercritical $\mathrm{CO}_{2}$. Chem Commun 2194

Moineau J, Pozzi G, Quici S, Sinou D (1999) Palladium-catalyzed Heck reaction in perfluorinated solvents. Tetrahedron Lett 40:7683

Munoz-Moniz O, Quintanar-Audelo M, Juaristi E (2003) Reexamination of $\mathrm{CeCl}_{3}$ and $\mathrm{InCl}_{3}$ as activators in the diastereoselective Mukaiyama aldol reaction in aqueous media. J Org Chem 68:1622

Okuhara T (2002) Water-tolerant solid acid catalysts. Chem Rev 102:3641

Otto S, Engberts JBFN (1999) A systematic study of ligand effects on a Lewis-acid-catalyzed Diels-Alder reaction in water. Water-enhanced enantioselectivity. J Am Chem Soc 121:6798

Otto S, Bertoncin F, Engberts JBFN (1996) Lewis acid catalysis of a Diels-Alder reaction in water. J Am Chem Soc 118:7702

Otto S, Boccaletti G, Engberts JBFN (1998) A chiral Lewis-acidcatalyzed Diels-Alder reaction. Water-enhanced enantioselectivity. J Am Chem Soc 120:4238

Paganelli S, Zanchet M, Marchetti M, Mangano G (2000) Hydroformylation of functionalized olefins catalyzed by water-soluble rhodium carbonyl complexes. J Mol Catal A Chem 157:1

Pathirana Hema MKK, Maithreepala RA (1997) Photodegradation of 3,4-dichloropropionamide in aqueous $\mathrm{TiO}_{2}$ suspensions. J Photochem Photobiol A Chem 102:27 
Petrier C, Jeunet A, Luche JL, Reverdy G (1992a) Unexpected frequency effects on the rate of oxidative processes induced by ultrasound. J Am Chem Soc 114:3148

Petrier C, Micolle M, Merlin G, Luche JL, Reverdy G (1992b) Characteristics of pentachlorophenate degradation in aqueous solution by means of ultrasound. Environ Sci Technol 26:1639

Pillai UR, Sahle-Demessie E, Varma RS (2002) Feature article: Environmentally friendlier organic transformations on mineral supports under non-traditional conditions. J Mater Chem 12:3199

Poonkodi SPR, Anbalagan K (2001) Outer-sphere redox reactions of cobalt(III)-amine complexes. A solvent, chelation and temperature-dependence kinetic study. Transition Met Chem $26: 212$

Raner KD, Strauss CR, Trainer RW, Thorn JS (1995) A new microwave reactor for batchwise organic synthesis. J Org Chem 60:2456

Rogers RD, Seddon KR (Eds) (2002) Ionic liquids: industrial applications for green chemistry. Oxford University Press, New York

Rylander PN (1979) Catalytic hydrogenation in organic synthesis. Academic Press, New York

Rylander PN (1985) Hydrogenation methods. Academic Press, Orlando, Fla.

Sangrama KS, Wei L, Lynne AS, Jayant K, Ashok LC (2002) Biocatalytic polymerization of $p$-cresol: an in-situ NMR approach to understand the coupling mechanism. Macromolecules 35:9990

Schmid A, Witholt B, Feiten H, Panke S (2001) Biocatalytic epoxidation of vinylaromatic compounds. PCT Int Appl WO 0136654

Shaw RW, Brill TB, Clifford AA, Eckert CA, Franck EU (1991) Supercritical water. A medium for chemistry. Chem Eng News 69:26

Shimizu S, Shirakawa S, Seiji S, Yasuyuki K, Hirai C (2000) Novel water-soluble calix[4]arene ligands with phosphane-containing groups for dual functional metal-complex catalysts: the biphasic hydroformylation of water-insoluble olefins. Angew Chem Int Ed Engl 39:1256

Shirakawa S, Shimizu S, Sasaki Y (2001) Rhodium-catalyzed biphasic hydroformylation of 4-octene using water-soluble calix[4]arene-phosphine ligands. New J Chem 25:777

Smidt J, Hafner W, Jira R, Sieber R, Sedlmeier J, Sabel A (1962) Palladium chloride-catalyzed oxidation of olefins. Angew Chem Int Ed Engl 1:80

Strauss CR (1999) Invited review. A combinatorial approach to the development of environmentally benign organic chemical preparations. Aust J Chem 52:83

Strauss CR, Trainer RW (1998) Reactions of ethyl indole-2-carboxylate in aqueous media at high temperature. Aust $\mathbf{J}$ Chem 51:703 and references cited therein

Tanaka K (Ed) (2003) Solvent-free organic synthesis. Wiley-VCH, Weinheim

Tin K, Wong N, Li R, Li Y, Li X (1999) Studies on catalytic hydrogenation of citral by water-soluble palladium complex. J Mol Catal A Chem 137:113

Togo H, Hirai T (2003) Environmentally-friendly Wohl-Ziegler bromination: ionic-liquid reaction and solvent-free reaction. Synlett 702

Toth I, Hanson BE, Davis ME (1990) Novel chiral water soluble phosphines II. Applications in catalytic asymmetric hydrogenation. Tetrahedron Asymmetry 1:895

Uchida I, Umeda M, Ito T Jpn. Kokai Tokkyo Koho (2002) Method and apparatus for electrolytic recycling of metals in etchant wastes without generating hazardous materials. JP 2002194580
Varma RS (1999) Solvent-free organic syntheses. Green Chem 1:43 Varma RS (2000a) Expeditious solvent-free organic syntheses using microwave irradiation. In Anastas, PT, Heine L, Williamson T (eds) ACS Symp Ser 767, American Chemical Society, Washington, DC, p 292

Varma RS (2000b) In: Tundo P, Anastas PT (eds) Green chemistry: challenging perspectives. Oxford University Press, Oxford, p 221

Varma RS (2001) Solvent-free accelerated organic syntheses using microwaves. Pure Appl Chem 73:193

Varma RS (2002a) In Loupy A (ed) Microwaves in organic synthesis. Wiley-VCH, Weinheim, p 181

Varma RS (2002b) Clay and clay-supported reagents in organic synthesis. Tetrahedron 58:1235

Varma RS (2002c) Advances in green chemistry: chemical syntheses using microwave irradiation. Astrazeneca Research Foundation India, Bangalore, India. (free copy available from: http:/ azrefi@astrazeneca.com)

Varma RS, Kumar D (1998) Surfactant pillared clays as phase transfer catalysts: a facile synthesis of $\alpha$-azidoketones from $\alpha$ tosyloxyketones and sodium azide. Catal Lett 53:225

Varma RS, Naicker KP (1998) Surfactant pillared clays in phase transfer catalysis: A new route to alkyl azides from alkyl bromides and sodium azide. Tetrahedron Lett 39:2915

Varma RS, Pitchumani K, Naicker KP (1999a) Triphasic catalyst systems based on surfactant/clay composites. Facile synthesis of cyano, thiocyano and hydroxy compounds using a triphasic catalyst. Green Chem 1:95

Varma RS, Naicker KP, Aschberger J (1999b) A facile preparation of alkyl azides from alkyl bromides and sodium azide using 18crown-6 ether doped clay. Synth Commun 29:2823

Varma RS, Naicker KP, Kumar D (1999c) Can ultrasound substitute for a phase-transfer catalyst? Triphase catalysis and sonochemical acceleration in nucleophilic substitution of alkyl halides and $\alpha$-tosyloxyketones: synthesis of alkyl azides and $\alpha$ azidoketones. J Mol Cat A Chemical 149:153

Wang X, Zhang B, Cao Y (1996) Sensitized photoisomerization of a norbornadiene derivative in aqueous solution. Yingyong Huaxue 13:17; Chem. Abstr. 126, 67306

Wasserscheid P, Keim W (2000) Ionic liquids - new "solutions" for transition metal catalysis. Angew Chem Int Ed Engl 39:3772

Wei CM, Li CJ (2002) Grignard type reaction via $\mathrm{C}-\mathrm{H}$ bond activation in water. Green Chem 4:39

Wei M, Musie GT, Busch DH, Subramaniam B (2002) $\mathrm{CO}_{2}$-expanded solvents: unique and versatile media for performing homogeneous catalytic oxidations. J Am Chem Soc 124:2513

Westacott RE, Johnston KP, Rossky PJ (2001) Simulation of an $S_{N} 1$ reaction in supercritical water. J Am Chem Soc 123:1006

Wipf P, Ribs S, (2001) Water-accelerated tandem Claisen rearrangement-catalytic asymmetric carboalumination. Org Lett 3:1503

Wu W, Li CJ (2003) A highly regio- and stereoselective transition metal-catalyzed hydrosilylation of terminal alkynes under ambient conditions of air, water, and room temperature. Chem Commun 1668

Younkin TR, Connor EF, Henderson JI, Friedrich SK, Grubbs RH, Bansleben DA (2000) Neutral, single-component nickel(II) polyolefin catalysts that tolerate heteroatoms. Science 287:460

$\mathrm{Yu} \mathrm{R}, \mathrm{Hu} \mathrm{G}$ (2001) Photolysis of 2,6-dinitrotoluene and m-nitrochlorobenzene in water. Huaqiao Daxue Xuebao 22:309; Chem Abstr 136, 74041

Zhang W, Hua X, Meng Y, Venkatraman S, Keh CCK, Li CJ (2000) A periodical analysis of metal-mediated carbon-carbon bond formations in aqueous media. Recent Res Dev Org Chem 4:397 